\title{
Politización y despolitización en el pensamiento de Carl Schmitt
}

Ricardo J. Laleff Ilieff*

DOI 10.20399/P1982-999X.2016v1n2pp63-75

\begin{abstract}
Resumen
El presente trabajo analiza el concepto de politicidad en el pensamiento de Carl Schmitt destacando la simbiótica relación entre politización y despolitización. Se argumenta que politización y despolitización resultan el anverso y el reverso del alegado schmittiano sobre lo político por lo que resulta imposible pensar estos elementos de manera disociada. En este sentido, no solo se trata de colaborar con la reflexión en torno a la autonomía de lo político sino también sobre el problema de su acotación. Por consiguiente, este ejercicio hermenéutico versa también sobre la relación entre Estado y sociedad y las distintas formas en las cuales Schmitt analizó dicho vínculo. Finalmente, tras centrarse en algunas de sus obras del período weimariano, el trabajo efectúa una breve reflexión sobre el problema de la politicidad y del Estado total en Estado, movimiento, pueblo.
\end{abstract}

Palabras-clave: Politización; Despolitización; Schmitt; Politicidad.

\begin{abstract}
This article analyses the politicity in the thought of Carl Schimtt. Its focus is on the simbiotic relationship between politicization and depoliticization. It argues that both politicization and depoliticization constitute the obverse and reverse of Schmitt's concept of politics, making it impossible to think of these two elements disscociated from each other. It does not only try to reflect on the autonomy of politics, but also on the problem of its restriction. Therefore, this hermeneutical exercise also deals with the relationship between State and society and the diferent ways in which Carl Schmitt analysed it. Overall, after focusing on some of his work from the Weimar period, this article makes a brief reflection about this problem seen in State, movement, people, published in the same year Adolf Hitler rose to power.
\end{abstract}

Key-words: Politicization; Despoliticization; Schmitt; Politicity.

\section{Introducción}

Lo político no puede prescindir de la despolitización. Politización y despolitización representan las dos caras de la politicidad. Toda aserción de lo político, toda conjura de lo político frente a los peligros y las amenazas que lo acechan, frente a las negaciones recurrentes que provienen de paradigmas modernos, no desconoce la necesidad de la despolitización. En el pensamiento de Carl Schmitt se trata de una simbiótica vinculación entre politización y despolitización al interior de un alegato sobre lo político, es decir, se trata de dos aspectos constitutivos de la politicidad. En este sentido, reivindicar lo político no significa sostener meramente su necesidad o inexorabilidad sino también admitir la exigencia de que algo se mantenga despolitizado o se le sustraiga, o se le disminuya, la posibilidad de politizarse. De modo que la despolitización no es un acto de clausura ni un cierre definitivo sino un proceso que se produce y se reproduce en todo ordenamiento en paralelo a la politización. Por consiguiente, este trabajo pretende pensar no sólo la autonomía de lo político sino también de su acotación, cuestiones presentes en la obra schmittiana aunque exploradas de manera desigual.

\footnotetext{
*Doctor en Ciencias Sociales por la Universidad de Buenos Aires, profesor de teoría política en dicha casa de estudios y becario del Consejo Nacional de Investigaciones Científicas y Técnicas. E-mail: lilieff@hotmail.com
} 
Ahora bien, para avanzar en la tarea propuesta es menester destacar cierta dualidad por parte de Schmitt en el tratamiento de la despolitización, ya que en algunos de sus trabajos parece versar sobre la neutralización del conflicto al interior de la unidad política mientras que en otros se encuentra ligado al problema de la negación misma de la politicidad. De todas maneras, esta dualidad se acaba al establecerse una única conclusión: la despolitización puede fortificar lo político o puede hostigarlo procurando suprimirlo. Por consiguiente, la despolitización puede atentar o favorecer la politicidad, puede solventar la neutralización del conflicto de todo agrupamiento o debilitarlo multiplicando las cristalizaciones perniciosas. Un desenlace como este interroga el problema de la conducción de dicho proceso y por tanto se pregunta sobre la materia misma de lo político.

Como ya se ha dicho, para Schmitt una de las aristas de la despolitización resulta nociva. Sin embargo, más allá de sus objetivos dañinos, no deja de ser evidente su fragilidad intrínseca. Dicho de forma más directa, la despolitización anhelada por el marxismo y el liberalismo -arquetipos al respecto- se encuentra destinada a fracasar al no poder llevarse a cabo íntegramente. Lo político implica un acto de demarcación, agrupamientos bien específicos, la defensa de una forma de vida que, necesariamente, se opone -o al menos se distingue- a otra. Sumado a ello, hay algo de la propia naturaleza del hombre que no puede escapar al imperio de lo político ${ }^{1}$. Lo político está destinado a persistir. Pero si efectivamente es así, es decir, si lo político no puede eliminarse completamente del mundo de los hombres, si la fuente de lo político no puede agotarse, si todo intento en este sentido es fútil, ¿por qué se preocupa Schmitt por los peligros que lo acechan $?^{2}$ En principio se podría decir que los efectos de estas tendencias no son del todo inicuos o inofensivos. Hay algo del orden de la estabilidad y de la existencia de todo ordenamiento que debe preservarse para garantizar la vida. Por otro lado, es cierto que liberalismo y marxismo no resultan iguales para Schmitt, pero en algunos pasajes de su autoría resultan casi equivalentes al compartir un mismo origen: son herederos de una época que pretende encontrar soluciones técnicoeconómicas a la vida del hombre pensando el surco de la electrificación ${ }^{3}$. Lo que marca Schmitt es que dichas expresiones poseen objetivos despolitizadores pero, aún así, sus acciones no dejan -no pueden no hacerlo- de inscribirse en el terreno de lo político. Liberalismo y marxismo pretenden destruir el único dispositivo que ha logrado -no sin tribulaciones- garantizar la vida en sociedad. Ambos recurren a la homogeneidad de ciertos ideales que ponderan una humanidad reconciliada, el fin de las clases sociales o el reino de la libertad más extendida entre individuos, pero desde la óptica schmittiana todo ello resulta mera palabrería. Pretender la homogeneidad del orbe y apelar a la humanidad como sujeto político es un engaño ${ }^{4}$. Los asuntos políticos habitan en la heterogeneidad, por eso el mundo es un pluriverso y no un universo político ${ }^{5}$. Aquí vuelve a ser necesario mostrar la paradoja señalada por el propio autor: toda tentativa por efectuar una despolitización total del mundo, por agotar todo resabio de politicidad

\footnotetext{
${ }^{1}$ SCHMITT, C. El concepto de lo político. Buenos Aires: Folios, 1984, p. 54.

${ }^{2}$ Esta pregunta es la que reposa, por ejemplo, detrás del análisis de Leo Strauss aEl concepto de lo político. Según Strauss, en dicho escrito Schmitt defiende una moralidad específica, por lo que su afirmación de lo político no es otra cosa que la afirmación de la moral (Luciano Nosetto, 2013). Otros comentaristas han contestado dicho interrogante apelando al costado teológico-político del jurista alemán (Heinrich Meier, 2008).

3 "El gran empresario no tiene un ideal distinto del de Lenin, a saber: conseguir una «tierra electrificada»”. SCHMITT, C. Catolicismo romano y forma política. Madrid: Tecnos, 2011, p. 16.

${ }^{4}$ SCHMITT, 1984, p. 51.

${ }^{5}$ Ibidem, p. 52.
} 
que existe en él, necesita de lo político para efectivizarse, necesita también de una forma política con capacidad decisoria. De esta manera, lejos de agotarse, lo político perdura.

Señaladas las coordenadas directrices de este trabajo, las líneas que siguen a continuación despliegan un argumento en torno al concepto de politicidad. Se arguye que la politicidad, tal como la entiende Schmitt, no puede ser concebida como pura politización dado que no se fundamenta en su expansión omnicomprensiva. La politización es sólo una cara de la politicidad pero no la única. Una mirada apresurada sugiere que la politicidad schmittiana es sólo politización, pura politización, pero en verdad la politicidad es también despolitización. Se trata de dos movimientos que se gestan en paralelo y se influencian mutuamente, simbióticamente. Esta suerte de acoplamiento entre ambos procesos se encuentra asociado con el concepto de neutralización y con los vínculos entre el Estado y la sociedad civil. De modo que este trabajo se estructura en una serie de apartados destinados a precisar estas cuestiones en algunas de las obras capitales del período weimariano pero también, a manera de señalamiento, se concluye con cierta mención orientadora en torno a uno de sus principales escritos durante el régimen nacional-socialista.

\section{La despolitización imposible}

El concepto de lo político tiene una inconfundible impronta estatal puesto que su precisión comienza destacando lo equivocado de igualar al Estado con lo político y de pensar lo político únicamente a través del Estado. Sin embargo Schmitt, aun con todo ese gesto de "negatividad" metodológica, no hace más que reforzar la importancia del Estado en la modernidad, de pensar la presencia de lo político en una situación histórica particular en la que el Estado se erige en el ápice de lo político. De modo que El concepto de lo político es la obra de un autor que piensa desde la modernidad a la política y piensa al Estado como un dispositivo propio del desarrollo técnico ${ }^{6}$. Este es el sentido inicial del texto cuando parece articularse en base a la lógica protecciónobediencia de Thomas Hobbes. Dicha tematización del pensador británico representa para Schmitt la herramienta fundamental que articula los vínculos sociales y comunitarios. Sin embargo, el jurista alemán advierte que el carácter contingente de la empresa estatal hace que no sea factible monopolizar a través suyo el sentido de lo político. En tal virtud, para entender lo político no basta con abordar al Estado ni apropiarse de distinciones propias de la moral, la estética o la economía. Así parece constituirse una suerte de esfera propia de lo político que, desde el decir de Leo Strauss, puede leerse como una especie de contradicción del autor en la medida que si Schmitt se refiere a regiones diferenciadas y criterios "autónomos de otras contraposiciones", entonces su postura queda enmarcada en la cultura burguesa a la cual se opone. Sin embargo, para Strauss, Schmitt no expresa cosa semejante sino que destaca una especificidad que no implica una compartimentación ${ }^{8}$. De hecho la crítica schmittiana al liberalismo es consciente de ello al sostener que en dicha corriente "es extraordinario

\footnotetext{
${ }^{6} \mathrm{La}$ lectura sobre la trascendencia de todo orden es posterior y ampliamente discutible.

${ }^{7}$ SCHMITT, 1984, p. 23.

8 "Un lector poco avezado podría llevarse la impresión de que, una vez que el liberalismo reconoció la autonomía de lo estético, de la moral, de la ciencia, de la economía, etc., a partir de ahora Schmitt, por su parte, pretende reconocer la autonomía de lo político, en contra del liberalismo pero continuando con las aspiraciones liberales de autonomía. Sin embargo, el entrecomillado de la palabra 'autonomía' en la expresión 'autonomía de los distintos dominios de la vida humana' demuestra ya cuán poco coincide Schmitt con esa concepción". STRAUSS, L. "Comentario sobre El concepto de lo político de Carl Schmitt". In: MEIER, H. Carl Schmitt, Leo Strauss y el concepto de lo político: sobre un diálogo entre ausentes. Buenos Aires: Katz, 2010, p. 138.
} 
con cuánta espontaneidad no sólo reconoce, fuera del ámbito político la 'autonomía' de los diferentes sectores de la vida humana, sino que los lleva a la especialización y aun al aislamiento total"9. Schmitt llega así a un criterio propio de lo político, la categoría amigo-enemigo, conceptualización "autónoma no en el sentido de que constituye un nuevo sector concreto particular, sino en el sentido de que no está fundada ni sobre una ni sobre algunas de las otras antítesis, ni es reductible a ellas" ${ }^{10}$. Dado que tal distinción expresa un "grado de intensidad" ", cualquier otra contraposición pueda constituirse en política ${ }^{12}$ mientras que lo político puede valerse, "en la realidad psicológica"13, de otras contraposiciones como recursos legitimadores de su accionar ${ }^{14}$. De todas maneras, "lo que es moralmente malo, estéticamente feo y económicamente dañino, no tiene necesidad de ser por ello mismo también enemigo; lo que es bueno, bello y útil no deviene necesariamente amigo, en el sentido específico, o sea político, del término" 15 . En consecuencia no hay necesidad de que el enemigo sea "moralmente malo, o estéticamente feo; no debe necesariamente presentarse como competidor económico y tal vez puede también parecer ventajoso concluir negocios con él. El enemigo es simplemente el otro, el extranjero"16.

Quedan así expresadas al menos dos cuestiones capitales: la primera destaca la variabilidad del concepto de lo político, variabilidad que niega una cualidad totalizante e inmutable en la medida de que el amigo o el enemigo no se constituye en términos ontológicos sino circunstanciales, y la segunda denota que la resolución de los conflictos no depende de un tercero imparcial sino de la propia dinámica de los implicados. En tal virtud lo que subyace es la "lucha"17, "la posibilidad real de la eliminación física" ${ }^{18}$.

Aquí no se pone en absoluto en cuestión el problema de si se considera reprobable o no, o si se considera una herencia atávica de los tiempos bárbaros, el hecho de que los pueblos continúen agrupándose en base al criterio amigo y enemigo, ni se determina si se espera que tal distinción pueda un día ser abolida de la tierra, o bien si se piensa que sería bueno y justo fingir, con fines pedagógicos, que no hay ya enemigos ${ }^{19}$.

No obstante, según Schmitt, esto no implica que:

la esencia de lo "político" no sea otra cosa que la guerra sangrienta y que toda tratativa política deba ser una batalla militar, ni que todo pueblo esté ininterrumpidamente contrapuesto a todos los demás en la alternativa de amigo o enemigo, ni que la correcta elección política no pueda consistir justamente en evitar la guerra. La definición aquí dada de "político" no es ni belicista ni militarista, ni imperialista, ni pacifista. Ella no representa siquiera un intento de elevar la guerra

\footnotetext{
${ }^{9}$ SCHMITT, 1984, p. 69.

${ }^{10}$ Ibidem, p. 23.

${ }^{11}$ Ibidem, p. 23.

12 Ibidem, p. 23.

13 Ibidem, p. 23.

${ }^{14}$ Ibidem, p. 24.

15 Ibidem, p. 24.

${ }^{16}$ Ibidem, p. 23.

${ }^{17}$ Ibidem, p. 29.

${ }^{18}$ Ibidem, p. 30.

${ }^{19}$ Ibidem, p. 25.
} 
victoriosa o la revolución lograda a "ideal social", puesto que guerra o revolución no son nada de "social" ni de "ideal"20.

Ahora bien, dado que la díada amigo-enemigo es existencial y que el enemigo es quien amenaza la propia forma de vida, la resolución última de esa contradicción es la guerra. Esto no quiere decir que Schmitt mantenga una visión teleológica que conduzca inexorablemente a la guerra, ni tampoco que viera en ella a una forma de alcanzar el "progreso de la humanidad". Lo que se cifra detrás de esta postura es que el momento decisivo que resuelve el antagonismo constitutivo es la guerra: "es desde esta posibilidad extrema que la vida del hombre adquiere su tensión específicamente política" ${ }^{21}$. Un mundo desprovisto de esta contradicción extrema — tal como pretenden las principales perspectivas despolitizadoras - resultaría ilusorio y significaría "un mundo sin política". En ese panorama imaginario "podría tal vez haber contraposiciones y contradicciones muy interesantes, competencias e intrigas de todo tipo" pero "no habría ninguna contraposición sobre la base de la cual se pudiese requerir a los hombres el sacrificio de su propia vida, o autorizarlos a derramar sangre y matar a otros" ${ }^{22}$. Inclusive el despliegue de una "última guerra definitiva de la humanidad" que procurara anular todas las líneas de enemistad, no sería más que una reafirmación de lo político con el agravante de que el otro pasaría a ser deshumanizado ${ }^{23}$ y criminalizado ${ }^{24}$.

Aunque la tradición iniciada por Marx y Engels propugne una sociedad sin clases, existe un enfrentamiento previo al establecimiento del comunismo que debe articularse en base a la lógica amigo-enemigo. En otros términos, para llevar a cabo la despolitización, el marxismo debe primero "politizarse". Schmitt le reconoce un gesto de politización aglutinador fenomenal, ya que el marxismo

Busca concentrar en una única batalla final contra el último enemigo de la humanidad todas las batallas de la historia universal, en la medida en que reúne a todas las burguesías del mundo en una sola y a todos los proletarios en uno solo, y de ese modo alcanza una poderosa forma de reagrupamiento en base a la distinción amigo-enemigo ${ }^{25}$.

Sin embargo, la influencia de las clases en dicha lógica implica cierto nivel de abstracción que obstaculiza su capacidad de concreción. Esto se debe a que los

\footnotetext{
${ }^{20}$ SCHMITT, 1984, p. 30.

${ }^{21}$ Ibidem, p. 32.

22 Ibidem, p. 32.

23 "Tales guerras son necesariamente de una particular intensidad e inhumanidad, puesto que, superando lo 'político', descalifican al enemigo inclusive bajo el perfil moral, así bajo todos los demás aspectos, y lo transforman en un monstruo feroz que no puede ser sólo derrotado sino que debe ser definitivamente destruido, es decir que no debe ser ya solamente un enemigo a encerrar en sus límites". (Ibidem, p. 33).

${ }^{24}$ En el Nomos de la Tierra Schmitt analizó la discriminación del enemigo haciendo mayor énfasis en la caída de un paradigma jurídico de regulación de las relaciones entre Estados. Además expresó una reflexión mucho más acabada sobre el final de una época en donde la guerra resultaba una forma de reconocimiento entre los leviatanes, cuestión que cambió tras la primera gran contienda, en donde lo bélico decantó en "crimen", "al convertirse la guerra por una lado, en acción punitiva en el sentido del moderno derecho criminal, el adversario, por otro lado, ya no puede ser un iustus hostis. Ya no se libra una guerra contra él, como tampoco se libra una guerra contra un pirata, que es un enemigo en un sentido muy distinto, del adversario de guerra según el derecho de gentes europeo. Ha cometido un delito en el sentido criminal, o sea el 'crimen del ataque'. Por lo tanto, la acción contra él no es guerra al igual que la acción de la policía estatal contra un gangster no es guerra”. (SCHMITT, C. El Nomos de la Tierra: en el derecho de gentes del "Ius Publicum Europaeum". Buenos Aires: Struhart, 2005, p. 114).

${ }^{25}$ SCHMITT, 1984, p. 71.
} 
agrupamientos son demasiado genéricos ${ }^{26}$.

Esta imposibilidad del marxismo no sólo es responsabilidad de su rasgo internacionalista, también encuentra sus causas en sus propios fundamentos al estar atravesados por una contradicción insalvable producto de su intento por negar lo político. No es un dato menor que Marx fuera catalogado por Schmitt como un "experto económico" y como el máximo representante del siglo dominado por la economía ${ }^{27}$. En esa operación hay un encierro evidente y por consiguiente un desplazamiento, pues ya no parece ser necesario continuar discutiendo políticamente ni con Marx ni con el marxismo al señalarse su raíz económica -claro que Schmitt nunca llevó este gesto hasta sus últimas consecuencias-. Esta postura le quita relevancia el aporte marxiano acerca de la dinámica del capitalismo y a su ajuste de cuentas con el idealismo alemán, pues lo importante para Schmitt es destacar su intento malogrado por neutralizar lo político y, paradójicamente, su necesidad imperiosa de apelar a él para hacerse posible fácticamente.

Liberalismo y marxismo no sólo comparten un mismo origen sino también una misma metodología. Sus intentos despolitizadores y neutralizadores de lo político se apoyan en el imperio de la técnica. Sin embargo, la técnica es "siempre sólo instrumento $\mathrm{y}$ arma, y por el hecho de que sirve a todos no es neutral" 28 . Aun una esfera aparentemente indiferente como la técnica, esconde una mano que la utiliza, siendo esa mano ya no invisible, sino la expresión misma de la perdurabilidad de lo político $^{29}$. Sobre esta cuestión versa el próximo apartado.

\section{La neutralización del conflicto}

La indagación sobre la politicidad de la técnica se encuentra cabalmente desarrollada en la conferencia "La época de las neutralizaciones y despolitizaciones" de 1929, aunque esto no implica una relación de continuidad entre dicho texto y El concepto de lo político sino más bien cierta complementación que permite profundizar temáticas recurrentes del pensamiento schmittiano. Por ello un breve análisis de la cuestión de la técnica nos permitirá clarificar la relación entre politización y despolitización señalada en el anterior apartado.

En dicha conferencia pronunciada en España Schmitt indaga sobre el problema del imperio de la técnica, el último centro de referencia de la historia europea. Según el oriundo de Plettenberg todo centro aparece como neutral debido a la necesidad de hacer posible la vida en conjunto. Los centros son ámbitos en donde los conflictos parecen disolverse en el marco de ciertos niveles de consenso. No importa sobre qué se discuta, lo importante es que si esa discusión tiene implicancias políticas, entonces las soluciones se encuentran en ese centro. Pero una vez agotada sus potencialidades — una vez que los conflictos ya no se presentan como susceptibles de ser solucionados en élse establece otro ámbito donde las disputas tienen lugar así como su consecuente neutralización:

\footnotetext{
${ }^{26}$ Toda estrategia revolucionaria para operativizarse necesita de la política, necesita de hacer un análisis de los sectores sociales que pueden favorecer el camino hacia la revolución. Esto no aparece en $E l$ concepto de lo político pero sí está claro en Teoría del partisano al diferenciarse a Mao de Lenin y sostener que el líder chino entendió la enemistad de una forma más concreta y por eso más factible de operativizarse que el líder soviético, quien al universalizar un antagonismo de origen "teórico", terminó por convertirlo en una imposibilidad política. Según Schmitt, Mao entendió que el ámbito en donde se desarrolla la acción política moderna no puede desconocer la esfera telúrica.

${ }^{27}$ SCHMITT, C. "La época de las neutralizaciones y las despolitizaciones". In: SCHMITT, 1984, p. 83

${ }^{28}$ Ibidem, p. 87.

${ }^{29}$ Ibidem, p. 90.
} 
Una vez que un sector se convierte en el centro de referencia, los problemas de los demás sectores son resueltos desde su punto de vista y sólo valen en adelante como problemas de segundo rango, cuya solución surge por sí misma o bien resueltos los problemas del sector central $^{30}$.

Lo mencionado debe ser entendido en el marco de un proceso histórico como el de la secularización occidental que "trata de cuatro grandes, simples, pasos" ${ }^{31}$. No en vano el primer centro de referencia es el teológico, el segundo el metafísico y el moral, el tercero el económico y el cuarto el técnico ${ }^{32}$. En esta conferencia Schmitt indica puntillosamente que la técnica puede servirle a las fuerzas más dispares. En cierta medida considera que su profesada neutralidad resulta fidedigna al prescindir de valores predeterminados pero, por otro lado, esta pretendida indiferencia no es del todo rigurosa ya que se necesita de valores que la conduzcan. Lo político -entendido como la defensa de una determinada forma de vida- no deja nunca de operar en el mundo más allá de sus fuerzas negadoras. Inclusive se podría decir que el sustrato de cada centro es lo político que permanece más allá de los centros ficcionales de resolución. Esto no representa una incoherencia si se entiende que los centros de referencia no son más que construcciones de los hombres que implican discursos legitimadores, ámbitos de disputas pero también de negociación que resuelven aspectos de la vida sin por ello ocultar el trasfondo existencial, si se quiere más primario, en donde se juega la supervivencia de los agrupamientos.

Nótese que en la propia genética del Leviatán se encuentra la relación de la forma política característica de la modernidad con la técnica, dado que el Estado surgió - tal como teorizó Hobbes - como un mecanismo cuyo objetivo consistía en evitar el derramamiento de sangre producto de las luchas confesionales del siglo XVII. De manera que su presencia implicaba la efectivización de un tipo de politización que conllevaba una neutralización necesaria. Las sectas en disputas debían dejar de estarlo, la unidad política reclamaba la pacificación. Por ello el principal objetivo del Estado leviatánico consiste en despolitizar a la sociedad en la medida en que él mismo se carga de politicidad. Aquí aparece la diferencia entre este objetivo primario y genético del Estado moderno y las tentativas despolarizadoras del liberalismo y del marxismo que pretenden erradicar lo político sea mediante el imperio de las organizaciones sociales, de la libertad más irrestricta del individuo o de la lucha entre las clases sociales. La unidad política necesita de una instancia que haga posible la vida del hombre protegiéndolo de los peligros internos como de los externos. Por ello, "el protego ergo obligo es el cogito ergo sum del estado" 33 . De allí que impugne el surgimiento de asociaciones que debiliten al Estado. Justamente el problema de las visiones pluralistas como las de George Cole y Harold Laski es que corroen y destruyen al orden concreto y su capacidad para defender la vida de los súbditos. El horizonte implica estar presto a neutralizar la guerra civil:

$\mathrm{Si}$ en el interior del estado existen partidos organizados, en condiciones de brindar a sus miembros una seguridad mayor que el

\footnotetext{
${ }^{30}$ SCHMITT, 1984, p. 83.

${ }^{31}$ Ibidem, p. p. 78.

32 Recuérdese que Schmitt ya había abordado - aunque desde otro camino- la cuestión de la secularización en Teología política. Aquí también lo teológico aparece como el origen, lo inicial, pero parece no retornar en el decurso de la explicación.

${ }^{33}$ SCHMITT, 1984, p. 48.
} 
estado, entonces en el mejor de los casos el estado se convierte en un apéndice de esos partidos y el ciudadano individual sabe perfectamente a quien debe prestar obediencia ${ }^{34}$.

Con esto Schmitt no hace referencia a un mundo pacificado. Una cosa son las contradicciones en la unidad política y otra cosa son las disputas entre Estados. Una neutralización es vista de forma positiva y la otra es una despolitización estéril en la medida en que no resulta factible — pero aun así conserva su peligrosidad - pues la existencia de un "Estado universal" que borre la distinción amigo-enemigo y aleje el peligro de la guerra es una falacia ${ }^{35}$. En suma, la conflictividad siempre estará presente:

Si los distintos pueblos, religiones, clases y demás grupos humanos de la Tierra fuesen tan unidos como para hacer imposible e impensable una guerra entre ellos, si la propia guerra civil, aun en el interior de un imperio que comprendiera todo el mundo, no fuese ya tomada en consideración, para siempre, ni siquiera como simple posibilidad, si desapareciese hasta la distinción amigo y enemigo, incluso como mera eventualidad, entonces existiría solamente una concepción del mundo, una cultura, una civilización, una economía, una moral, un derecho, un arte, un esparcimiento, etcétera, no contaminados por la política, pero no habría ya ni política ni estado ${ }^{36}$.

En los trabajos repuestos Schmitt da cuenta que los intentos liberales de neutralización y despolitización tienen "un preciso sentido político y están dirigidas polémicamente" por lo que no ignora que el Estado cumple una función relevante para esta corriente, ya que el liberalismo "trató de vincular lo 'político' desde el punto de vista de lo "ético' para subordinarlo a lo 'económico",37. Con suma ironía, el autor afirma que no se puede decir que "los liberales de todos los países" no "hayan hecho menos política que otros hombres", pues hasta "celebraron las más diversas alianzas con elementos e ideas no liberales" 38 . El liberalismo necesita del Estado para conducir, a través de la libertad económica, el avance de la tecnificación como forma última de la despolitización:

El concepto político de lucha se convierte, en el pensamiento liberal, sobre el plano económico en competencia y sobre el "espiritual" en discusión, en lugar de una distinción clara de las situaciones diferentes de "guerra" y de "paz" se instaura una dinámica de competencia eterna y de discusión eterna. El estado deviene sociedad y precisamente sobre el plano ético espiritual se transforma en una concepción ideológico-humanitaria de la humanidad, mientras que sobre otro plano se convierte en la unidad técnico-económica de un sistema unitario de producción y de intercambio ${ }^{39}$.

¿Cómo puede ser entendida la afirmación schmittiana sobre el carácter histórico del Estado por un lado y, por otro, que su escrito se vertebre sobre la matriz hobbesiana? De vuelta aparece la necesidad de extender lo ya dicho en la introducción. Cuando

\footnotetext{
${ }^{34}$ SCHMITT, 1984, p. 49.

35 Ibidem, p. 50.

${ }^{36}$ Ibidem, p. 50.

${ }^{37}$ Ibidem, p. 57

38 Ibidem, p. 66.

${ }^{39}$ Ibidem, p. 69.
} 
Schmitt escribió El concepto aún no había decretado la muerte definitiva del Estado, como sí lo haría de forma conclusiva en 1938 El Leviatán en la teoría del Estado de Thomas Hobbes y en 1963 en la introducción de la última edición de El concepto. Por lo tanto, el anclaje estatalista implicaba un apoyo hacia la única estructura que se había mostrado capacitada para hacer posible la existencia política en la modernidad. Schmitt estaba pensando en el carácter neutralizador y despolitizador del Estado hacia la sociedad en términos del peligro de una guerra civil - posibilidad siempre patente en la debilidad de Weimar como, asimismo, en el imaginario europeo luego de la revolución rusa - al mismo tiempo que rescataba el aspecto de la política internacional durante el particular período de entreguerras. El concepto de lo político brindado por Schmitt es un concepto atravesado por la lógica que estructura al Estado. En este marco la reivindicación schmittiana de lo político es la reivindicación de la despolitización de la sociedad a manos del Estado. La comunidad se politiza para definir su existencia - algo que también se destaca en Teoría de la constitución- dando lugar a la sociedad moderna y su respectivo Estado, mientras que éste, como mecanismo, termina por darle unidad política a la sociedad a través de la relación protección-obediencia. De allí que el texto gire sobre una matriz hobbesiana de análisis visto el movimiento desde su final a su comienzo cuando, en verdad, la lógica analítica resulta a la inversa, puesto que el fundamento de los agrupamientos no reside en el lazo individual de la protecciónobediencia sino en el tópico velado de la comunidad ${ }^{40}$.

Por lo tanto, lo que se desea señalar es que Schmitt manejó dos criterios de politización y de neutralización que deben ser puestos en movimiento para entender algunas de sus elucubraciones. En un primer momento la comunidad se politiza para permitir su existencia - lo político es el único medio para ello- dando lugar así a la sociedad moderna que se despolitiza a manos del Estado con su objetividad técnica. Éste trata al cuerpo de súbditos en términos monistas para efectuar la neutralización de los conflictos internos mientras que tras sus fronteras la heterogeneidad se hace presente. En cambio, en un segundo momento, el Estado se despolitiza - producto del imperio de lo económico-técnico- politizándose la sociedad con sus organizaciones, generando un espacio en donde distintos grupos reclaman para así la obediencia de los individuos y ponen a estos en vínculos totales que despedazan la lógica que nutre al Leviatán. En esta segunda instancia la neutralización y despolitización de lo político se produce contra el Estado. Sobre este proceso, Schmitt se pronunció críticamente. De hecho, fue evidente en Legalidad y legitimidad al sostener la necesaria despolitización de la sociedad frente a un Estado total cuya presencia resultaba inobjetable. De modo que no se trata de un Schmitt estatalista sino de un Schmitt que veía en el Estado al único medio humano posible de permitir la existencia pacífica entre los hombres. Esto no siempre fue así, pues en algunas de sus obras colaboracionistas el Estado deja de ser el vértice de lo político como parte de una vuelta de página a la modernidad.

\section{Los caminos de la totalización}

La guerra de masas dio lugar a una política de masas que derivaría en una formación distinta de Estado. Schmitt la teorizaría a partir del concepto "Estado total", término que recibió la influencia de la categoría "mobilización total" de Ernst Jünger. De hecho, ya en la edición de 1932 de El concepto de lo político, aparecen ciertas menciones significativas a este nuevo tipo de Estado que comprendió arenas anteriormente no abarcadas. Esto no resultó un ejercicio extraordinario sino, más bien,

\footnotetext{
40 Sobre el problema de la comunidad y el fundamento de los agrupamientos desde una lectura no teológico-política, me permite sugerir mi trabajo citado en la bibliografía.
} 
la patente verificación de que hacia los primeros años de la década de 1930 las reflexiones schmittiana comenzarían a gestarse a la luz de este proceso histórico mayor de totalización política. En este contexto, para Schmitt las relaciones entre Estado y sociedad se modificaron. El Estado no representaba la síntesis de las tensiones producidas por el individuo, la familia y la sociedad civil. Si en el modelo característico de la modernidad la sociedad se define en contraposición al Estado, si de alguna manera todo espacio no-estatal es social, con el Estado total se produce un momento de extensión de lo político. Decir que el Estado total pensado por Schmitt es una suerte de caracterización del Estado de Bienestar es decir poco, es acercarse al problema pero solo rozarlo. Es cierto que el jurista expresó que la mencionada transformación adquiría mayor visibilidad en la arena de la economía -terreno anteriormente reservado para el accionar exclusivo del burgués- pero el proceso de totalización implicaba la participación de las masas en política y con ella el creciente peso de los partidos políticos y otras organizaciones, es decir, concernía a la expansión de estructuras que articulaban las demandas de las masas y que, al mismo tiempo, procuraban colonizar al Estado amparándose en ese poder creciente.

En Legalidad y Legitimidad (1932) Schmitt parece mostrar que el mayor proceso de expansión política implica un tipo de totalización negativa que asfixia la libertad de los hombres. En tal virtud, la realidad inexorable de la totalización, con la consecuente necesidad de adaptar la estructura estatal a estos tiempos -algo ya presente El guardián de la constitución (1932)-, generaba un problema. El mayor proceso de politización de la historia de Occidente, la mayor participación de los hombres en dicho acontecimiento, podía implicar la propia negación de lo político y la consecuente destrucción de la estatalidad moderna. En Legalidad y Legitimidad Schmitt responsabiliza a las fuerzas pluralista de ello.

Si como se ha señalado, en "Ética de Estado y Estado pluralista" Schmitt denuncia a Laski a Cole y a través de ellos a todo el liberalismo por ver en la partidización de la comunidad política la ruptura del vínculo protección-obediencia propio de la estatalidad inaugurada por Hobbes, en Legalidad y Legitimidad esta impugnación en Alemania recae sobre el propio sistema constitucional de la república de Weimar. Los convulsionados años que siguieron a la caída del imperio y precedieron al nazismo mostró a un Schmitt comprometido con dicho ordenamiento en un principio pero luego, en su distanciamiento, radicalizó una postura que en su escrito de 1932 asume la idea de defender la parte sustancial de la constitución contra las soluciones de compromiso. Esta postura no lo acercaba al nazismo. De hecho, la advertencia al respecto que se puede encontrar en sus páginas le permitió gestar años después una suerte de expiación de sus años colaboracionistas ${ }^{41}$. Pero lo importante de esto es que en su idea de salvar al país del peligro y forjar así una verdadera constitución alemana, residía un apoyo a los sectores más conservadores. Tras su exhortación a despojar a la constitución de su "contra-constitución", se escondía una idea de cambiar el ordenamiento en su conjunto. Para Schmitt las "contracciones" constitucionales republicanas entre su primera y su segunda parte "habilitaban la posibilidad de una ruptura del sistema con el acceso de grupos extremistas" y "los poderes extraordinarios propios del estado de excepción" ${ }^{2}$. Esta es la última tentativa de Schmitt en Weimar, tentativa dirigida a despojar a la constitución de sus elementos liberales para convertirla en algo distinto bajo el ropaje de los valores de la comunidad y la necesidad de salvar

\footnotetext{
${ }^{41}$ Recuérdese que hacia la década de 1950, en unas páginas preliminares a su trabajo de 1932, sostuvo que Legalidad y Legitimidad resultaba "una llamada de socorro" (LyL. 5) ante el peligro del extremismo nazi y comunista.

${ }^{42}$ SCHMITT, C. Legalidad y legitimidad. Buenos Aires: Struhart, 2002, p. 54.
} 
"la idea de una obra constitucional alemana"43.

Ese acto de despojo convertía a Weimar en algo distinto a Weimar. Fracasado el intento schmittiano de que el presidente del Reich se convirtiera en un efectivo poder neutro que permitiera mediar entre las posiciones antagónicas de los partidos de la república -tal como aparece en El guardián de la constitución-, en Legalidad y Legitimidad el peso de la argumentación no descansa tanto en las prerrogativas del presidente en definir el estado de excepción y en interpretar el articulo 48 de la constitución sino directamente en la modificación del ordenamiento constitucional. Dicho con otras palabras, hacia 1932 ya nada se podía hacer con los partidos políticos. Había que recuperar la unidad política frente a la particularidad de los partidos. El individuo debía ser recapturado por el Estado para gestar la obediencia quebrando el accionar de los grupos sociales. El voto plebiscitario ya no bastaba como salvaguarda. Había que recuperar además la idea de una comunidad alemana que se superpusiera sobre la conflictividad de la sociedad moderna. Por ello, tras la caída de la legitimidad dinástica luego de la Primera Gran Guerra, la burocracia profesional y las fuerzas armadas debían constituirse en el núcleo de un tipo de Estado administrativo -el equivalente al Estado total- en el sustento de "la legitimidad plebiscitaria del presidente del Reich, elegido por el pueblo alemán" ${ }^{4}$. Burocracia civil y militar eran el núcleo de la despolitización que tenía como ápice al presidente y a un pueblo que legitimaba plebiscitariamente.

Por consiguiente, Schmitt analiza en este punto un tipo de totalización irrefrenable cuyo signo negativo debía ser modificado. Los grupos sociales llevaban a cabo un tipo de totalización perniciosa para la vida en conjunto. No sólo le disputaban la obediencia del individuo al Estado sino que también buscaban colonizar al Estado, pero como dicha colonización sólo se desarrollaba fragmentariamente, el Leviatán terminaba despedazado e imposibilitado por actuar como instrumento de orden: "Un Estado pluralista de partidos no se hace "totalitario" en virtud de su fuerza ni de su energía, sino por debilidad; interviene en todos los dominios de la vida, porque tiene que dar satisfacción a las reivindicaciones de todos los intereses" ${ }^{45}$. Además nótese que desde el propio título de su trabajo Schmitt impugna la idea de la equiparación moderna entre legalidad y legitimidad o, mejor dicho, con la confusión de ver en la legalidad un criterio de legitimidad. Esto que ha sido tan bien desarrollado por Max Weber, es un elemento más que muestra el creciente alejamiento del autor del régimen weimariano: de pensar hacia 1931 quién debía ser el guardián de la constitución, un año después Schmitt piensa en recuperar sólo una parte de ella y así poder modificar las bases de todo el ordenamiento republicano.

Pero existe también una curiosa afirmación en Legalidad y Legitimidad: "para emprender la necesaria despolitización y librarse del Estado total se necesita una autoridad estable que sea capaz de restablecer esferas y dominios para una vida libre" 46 .

Schmitt ve en la totalización negativa de los grupos sociales el peligro de la libertad. Si el Leviatán garantiza la libertad de los hombres al permitir su vida de conjunto y garantizar la neutralización del conflicto social, un Estado total negativo no es otra cosa que un Estado que deja de ser Estado al ser controlado por las fuerzas sociales que lo hostigan. Ante eso no queda otra cosa que enfrentar este tipo de totalización con otro tipo de totalización que defienda la capacidad neutralizadora del Estado y que despolitice a la sociedad. Este tipo de politización extrema pone en riesgo

\footnotetext{
${ }^{43}$ SCHMITT, 2002, p. 118.

${ }^{44}$ Ibidem, p. 32.

45 Ibidem, p. 115

${ }^{46}$ Ibidem, p. 113.
} 
el balance que se debe dar junto a la despolitización. Si bien escapa el lapso temporal prefijado como objeto de estudio en este trabajo, cabe aquí realizar una breve mención en torno al problema de cómo Schmitt juzgó a la politicidad durante el nazismo o, para ser más exactos, cómo lo hizo en uno de sus escritos más proclives al régimen de Hitler.

En 1933 el jurista alemán editó Estado, movimiento, pueblo. Allí mantuvo la importancia del simbiótico movimiento entre politización y despolitización al sostener que estos tres componentes propios de la nueva unidad política germana enunciados en el título, permitieron superar a la conflictividad de la modernidad liberal. Cabe señalar que en dicho texto Schmitt concibe al Estado como el elemento propiamente técnicoburocrático, al movimiento como la estructura política por antonomasia y al pueblo como su elemento impolítico. Esta estructura trinitaria de la comunidad política marca roles al interior de algo que no puede ni debe ser dividido. Pero lo interesante aquí no es sólo que el Führer no posee una relevancia fundamental en esta estructura sino que llama la atención la calificación del pueblo como una figura impolítica en el marco de un proceso de totalización significativo. Según la perspectiva schmittiana enunciada en dicho trabajo, el pueblo no debe politizarse para evitar caer en los peligros de la cultura burguesa y el Estado debe ser reducido a mero instrumento de ejecución del movimiento.

\section{Consideraciones finales}

Las consideraciones aquí vertidas han pretendido señalar las ramificaciones del pensamiento schmittiano sobre lo político ya que no implica solamente el problema de su autonomía y de su evocación sino también de su acotación. Es por ello que se ha marcado la inexorabilidad que conlleva este ejercicio en torno a pensar el problema de la despolitización. En este sentido se ha destacado que la politicidad de los asuntos humanos y más específicamente de toda organización política no puede prescindir de llevar a cabo procesos despolitizadores. El punto es que la politización necesita de la despolitización -y viceversa- en la medida en que son el anverso y el reverso de la politicidad.

El rastreo de este problema ha implicado un trabajo hermenéutico de la obra schmittiana que termina por remarcar la presencia de un uso dual, pero no contradictorio, del concepto de despolitización. Por un lado se ha señalado la crítica schmittiana a los intentos despolitizadores y neutralizadores de lo político llevados a cabo por el liberalismo y el marxismo mientras que, por otro, se ha indicado la suerte de una visión positiva sobre los efectos de un tipo de despolitización destinada a neutralizar los conflictos al interior de la unidad política. De modo que mientras que el primer uso conlleva efectos negativos pero también estériles, el segundo es necesario para la vida en sociedad. Por lo tanto el problema consiste en la conducción de esa despolitización. A partir de allí se han repuesto cómo las consideraciones del autor sobre la técnica complementan estos puntos y cómo también permiten pensar el vínculo entre el Estado y la sociedad marcando marcando un corrimiento en el propio autor. Una vez que aparece la indagación en torno al Estado total, en torno a este tipo de Estado producto de la época de masas, Schmitt muestra que no sólo se trata del movimiento hobbesiano de la politización del Estado y la despolitización de la sociedad para evitar la guerra civil sino también del peligro que las propias organizaciones sociales se politicen de tal forma que terminen despedazando al Estado y conduciendo a la totalización hacia la asfixia de la libertad individual. Esto aparece en Legalidad y Legitimidad.

Finalmente ha sido necesario mostrar que el problema de la politicidad continúa 
en la obra schmittiana inclusive en su periodo colaboracionista. En Estado, movimiento, pueblo de 1933 Schmitt piensa que el panorama conflictivo de la modernidad ha sido superado y con él su organización característica. Sin embargo, paradójicamente, aparece señalado la necesidad de mantener al pueblo en su rasgo impolítico. Tras el advenimiento de Hitler no se trataba de encontrar un elemento neutral o superior a las partes como en Weimar sino de articular los distintos niveles propios de la estructura tripartita de la unidad política. Lo fragmentado volvía a desaparecer en el seno de una comunidad. En ese marco el esquema Estado-sociedad aparece en desuso no así la relación entre politización y despolitización ya que el movimiento adquiere el lugar de la conducción de un pueblo despolitizado y el Estado aparece como un mero órgano de ejecución. En definitiva lo que se ha querido mostrar es la presencia de una reflexión sobre lo político en la obra schmittiana que escapa al gesto de reivindicación, abarcándolo pero también excediéndolo. Es por ello que para Schmitt se trata de un sutil juego al interior de la politicidad que exige pensar y repensar hasta dónde lo político como objeto de defensa, hasta dónde lo político como instrumento y a partir de cuándo lo político se transforma en amenaza.

\section{Referências}

BEAUD, O. Les derniers jours de Weimar. Paris: Descartes et Cie, 1997.

LALEFF ILIEFF, R. "Schmitt y la comunidad. Lo velado, lo visible, lo oculto". In: ROSSI, M. (comp.). El lazo social desde la filosofía política. Buenos Aires: Grama, 2015.

MEIER, H. Carl Schmitt, Leo Strauss y El concepto de lo político: sobre un diálogo entre ausentes. Buenos Aires: Katz, 2010.

NOSETTO, L. "La afirmación de lo político. Carl Schmitt, Leo Strauss y la cuestión del fundamento". Papeles de Trabajo, a. 7, n. 12, 2013.

SCHMITT, C. Catolicismo romano y forma política. Madrid: Tecnos, 2011. "Ética de Estado y Estado pluralista". In: MOUFFE, C. (comp.) El desafío de Carl

Schmitt. Buenos Aires: Prometeo, 2011. "La época de las neutralizaciones y las despolitizaciones". In: SCHMITT, C. El concepto de lo político. Buenos Aires: Folios, 1984. "Sobre los tres modos de pensar la ciencia jurídica". In: SCHMITT, C. Posiciones ante el derecho. Madrid: Tecnos, 2012.

Der Begriff des Politischen: Text von 1932 Mit Einen Vorwort Und Drei Corollarien.

Berlín: Duncker \& Humblot, 1979.

. Der Hüter der Verfassung. Berlín: Duncker and Humblot, 1969.

El concepto de lo político. Buenos Aires: Folios, 1984.

. El Leviatán en la teoría del Estado de Thomas Hobbes. Granada: Comares, 2004.

La defensa de la constitución. Madrid: Tecnos, 1983.

El Nomos de la Tierra: en el derecho de gentes del "Ius Publicum Europaeum".

Buenos Aires: Struhart, 2005.

"Further development of the total state in Germany". In: SCHMITT, C. Four articles.

1931-1938. Corvallis: Plutarch Press, 2001.

. Legalidad y legitimidad. Buenos Aires: Struhart, 2002.

Staat, Bewegung, Volk; die Dreigliederung der politischen Einheit. Hamburgo:

Hanseatische Verlagsanstalt, 1933.

. Teología política. Madrid: Trotta, 2009.

Teoría de la constitución. Madrid: Alianza, 2011.

Teoría del partisano: acotación al concepto de lo político. Madrid: Trotta, 2010.

STRAUSS, L. "Comentario sobre El concepto de lo político de Carl Schmitt". In: MEIER, H.

Carl Schmitt, Leo Strauss y El concepto de lo político: sobre un diálogo entre ausentes.

Buenos Aires: Katz, 2010.

WEBER, M. Economía y Sociedad: esbozo de sociología comprensiva. México: FCE, 2014. 